\title{
CARACTERIZAÇÃo TECNOLÓGICA, PARA PRODUÇÃo DE CELULOSE, DA NOVA GERAÇÃO DE CLONES DE Eucalyptus DO BRASIL ${ }^{1}$
}

\author{
José Lívio Gomide ${ }^{2}$, Jorge Luiz Colodette ${ }^{2}$, Rubens Chaves de Oliveira² e Cláudio Mudado Silva²
}

\begin{abstract}
RESUMO - Foram analisados clones de Eucalyptus de última geração, pertencentes às principais empresas brasileiras de celulose. Os estudos consistiram numa caracterização tecnológica detalhada da qualidade das madeiras utilizadas no processamento fabril das empresas. Foram realizadas análise químicas detalhadas das madeiras e cozimentos kraft, simulando-se uma das modernas técnica de digestor contínuo. Os resultados indicaram a alta qualidade dos clones de Eucalyptus atualmente plantados no Brasil para produção de celulose.
\end{abstract}

Palavras chave: Clone, eucalyptus, carboidratos, celulose kraft e lignina.

\section{TECHNOLOGICAL CHARACTERIZATION OF THE NEW GENERATION OF Eucalyptus CLONES IN BRAZIL FOR KRAFT PULP PRODUCTION}

\begin{abstract}
Last generation of Eucalyptus clones pulped by the main Brazilian kraft pulp mills were used for this study. Detailed chemical analysis of the woods were carried out to establish the wood quality. Laboratory simulation of a modern continuous digester technique was used for pulp production. Results demonstrated the high quality of Eucalyptus clones wood that are being planted in Brazil for kraft pulp production.
\end{abstract}

Key words: Clone, eucalyptus, carbohydrates, kraft pulp and lignin.

\section{INTRODUÇÃO}

Este estudo teve como objetivo analisar a qualidade tecnológica da nova geração de clones de Eucalyptus das principais empresas brasileiras produtoras de celulose kraft branqueada. Objetivou-se, ainda, uma caracterização mais detalhada, que é normalmente realizada para estabelecimento da qualidade das madeiras utilizadas no processamento fabril das empresas brasileiras. As principais empresas nacionais produtoras de celulose kraft branqueada de eucalipto foram convidadas a participar deste estudo, fornecendo um de seus clones classificados entre os de melhor qualidade tecnológica.
Dez empresas aderiram ao projeto, e seus clones, por motivos de confidencialidade, foram codificados por letras, de A a J.

\section{MATERIAL E MÉTODOS}

Três árvores de um mesmo clone de Eucalyptus, apresentando as dimensões médias de DAP e de altura do plantio, foram obtidas de cada empresa participante. As árvores foram seccionadas em toretes com $50 \mathrm{~cm}$ de comprimento obtidos na base da árvore e nas alturas correspondentes a 25, 50, 75 e $100 \%$ da altura comercial. Como altura comercial foi considerada a altura total

\footnotetext{
${ }^{1}$ Recebido em 09.08.2004 e aceito para publicação em 25.11.2004.

${ }^{2}$ Departamento de Engenharia Florestal da Universidade Federal de Viçosa 36570-000 Viçosa, MG. E-mail:<jlgomide@ufv.br>.
} 
da árvore até o diâmetro de $6 \mathrm{~cm}$, sem casca. Os 15 toretes das três árvores foram transformados em cavacos, num picador laboratorial de disco, dotado de três facas e de duas peneiras classificadoras vibratórias, com aberturas de malhas de 40 x $40 \mathrm{~cm}$ e 5 x $5 \mathrm{~cm}$. Foi, ainda, realizada uma classificação manual, para eliminação de pedaços de cascas, de nós e de cavacos com defeitos de corte. Para a completa homogeneização dos cavacos, foi utilizado um misturador esférico mecânico com capacidade para $260 \mathrm{~L}$. Os cavacos, classificados e homogeneizados, foram secados ao ar para uniformização da umidade e para conservação contra eventual desenvolvimento de microrganismos e, posteriormente, armazenados em sacos de polietileno. Para obtenção das amostras utilizadas nas determinações de densidade básica, análises químicas e análises de fibras e para os cozimentos foi utilizada a técnica de quarteamento.

\section{Análises químicas das madeiras}

Uma amostra dos cavacos de cada clone foi transformada em serragem, com o uso de moinho Wiley, sendo a serragem classificada em peneiras de 40 e 60 mesh. As análises químicas das serragens foram realizadas após o acondicionamento em sala aclimatizada a 25 ${ }^{\circ} \mathrm{Ce} 50 \%$ de umidade relativa. As metodologias utilizadas para determinação da densidade básica e para as análises químicas foram as estabelecidas nas normas ABTCP e Tappi ou conforme especificado a seguir: densidade básica, conforme norma ABTCP; solubilidade em álcool/ tolueno: norma Tappi T264 om-82; solubilidade em diclorometano: norma Tappi T204 cm-97; lignina Klason insolúvel em ácido: conforme Gomide (1986); lignina Klason solúvel em ácido: conforme Goldschmid (1971); análise de carboidratos (açúcares): norma Tappi T249 cm-00, modificada; teor de grupos urônicos: segundo Englyst e Cummings (1984); teor de ácidos hexenurônicos: determinados de acordo com o método proposto por Vuorinen et al. (1996); análise de grupos siringil e guaiacil: conforme Lim (1992), por cromatografia líquida após oxidação com nitrobenzeno; e análise de grupos acetil: conforme Solar et al. (1987), modificada.

\section{Análises de fibras}

As análises das fibras foram realizadas na polpa celulósica, depois de coloração com azul de astra; posteriormente, foram feitas montagens em lâminas de vidro e medições de largura e espessura de parede, em microscópio óptico, com aumento de 40 vezes, e medições de comprimento, em lupa, com aumento de 10 vezes. As imagens microscópicas foram digitalizadas com câmera fotográfica e as dimensões, mensuradas utilizando-se o programa Image-Pro Plus versão 3.2. Além do uso de microscópico óptico foram, também, realizadas medições com equipamento automático Galai CIS-100, para determinação de "coarseness" e do número de fibras por grama.

\section{Simulação de cozimento contínuo}

Para simulação de cozimento contínuo em laboratório foi utilizado o Sistema de Simulação de Digestor Contínuo (SSDC) do Laboratório de Celulose e Papel da Universidade Federal de Viçosa, apresentado na Figura 1. O sistema consiste de um digestor "batch" de $6 \mathrm{~L}$ de capacidade, dotado de bomba de circulação, trocador de calor e controlador eletrônico de tempo e temperatura, sendo monitorado por computador. $\mathrm{O}$ digestor é acoplado a um conjunto de vasos acumuladores com aquecimento elétrico, permitindo a conexão de todos os vasos, individualmente, com o digestor. Aquecido e pressurizado, o sistema possibilita a utilização de diferentes licores de cozimento nos vasos acumuladores e o deslocamento do licor no digestor pelos licores dos acumuladores, simulando as diferentes zonas de cozimento de um digestor contínuo. Para simulação de um digestor contínuo, foi selecionado um processo de cozimento com vaso de impregnação, baixa temperatura de cozimento e injeções parceladas da carga de álcali. As condições adotadas para simulação de cozimento contínuo foram as seguintes: cavacos $=800$ gr a.s.; sulfidez $=25 \%$; carga de álcali efetivo = estabelecida experimentalmente para número kappa $18 \pm 0,5$; zona de vaporização $=20 \mathrm{~min}$ com vapor de 1,5 atm; zona de impregnação $=60 \%$ do AE, com L/ $\mathrm{M}$ de $5 / 1$, por $60 \mathrm{~min}$, a $135^{\circ} \mathrm{C}$; zona de cozimento: $40 \%$ do $\mathrm{AE}, \mathrm{L} / \mathrm{M}$ de $4 / 1$, por $150 \mathrm{~min}$, a $155^{\circ} \mathrm{C}$; zona de lavagem $=30 \mathrm{~min}$, com decréscimo da temperatura de $155^{\circ}$ para $95^{\circ} \mathrm{C}$.

Completado o cozimento, os cavacos foram removidos do digestor, por sucção a vácuo, e desfibrados em "hidrapulper" laboratorial com $20 \mathrm{~L}$ de capacidade, em consistência de $0,6 \%$. Além da determinação do rendimento depurado, do número kappa, da viscosidade e do álcali residual, foi determinado o teor de ácidos hexenurônicos. 


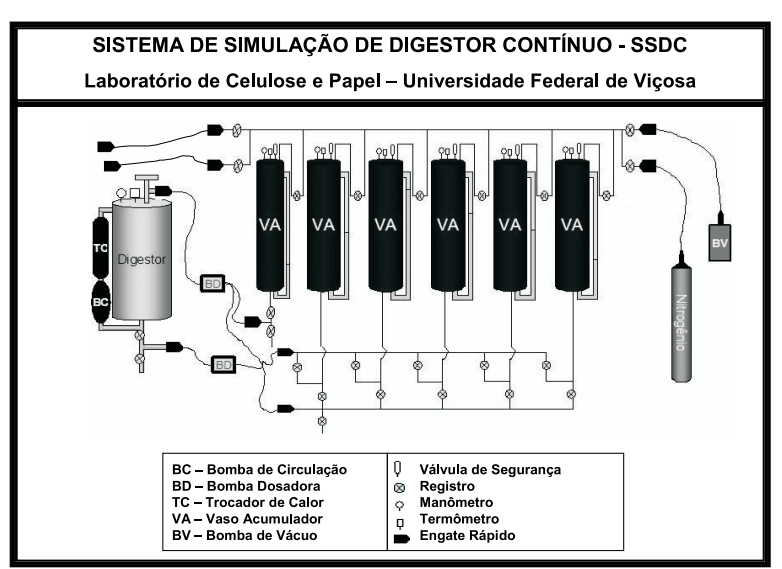

Figura 1 - Sistema de simulação de digestor contínuo (SSDC). Figure 1 - Simulation system for continuous digester (SSCD).

\section{RESULTADOS E DISCUSSÃO}

\section{Características silviculturais dos clones de Eucalyptus}

O Brasil apresentou, nas últimas décadas, uma invejável evolução no aspecto de produtividade das florestas de Eucalyptus, alcançando os mais elevados níveis mundiais de incremento médio anual (IMA). Os clones de Eucalyptus analisados neste estudo demonstraram a elevada produtividade dos clones das principais empresas nacionais, tendo dois clones atingindo IMA igual ou superior a $50 \mathrm{~m}^{3} / \mathrm{ha} / \mathrm{ano}$, e $80 \%$ dos clones exibiram incrementos acima de $40 \mathrm{~m}^{3} / \mathrm{ha} /$ ano (Quadro 1). Apenas um clone, o clone E, apresentou incremento inferior a $35 \mathrm{~m}^{3} / \mathrm{ha} / \mathrm{ano}$.

Quadro 1-Características silviculturais dos clones de Eucalyptus $\mathrm{sp}$

Table 1 - Silvicultural characteristics of Eucalyptus clones

\begin{tabular}{|c|c|c|c|c|}
\hline Clones & Espécies & DAP, & & IMA, $\mathrm{m}^{3} /$ \\
\hline$\overline{\mathrm{A}}$ & E.grandis $x$ urophylla & 17,7 & 26,9 & 52,9 \\
\hline B & E. grandis (híbrido) & 17,7 & 19,6 & 46,0 \\
\hline $\mathrm{C}$ & E.grandis $x$ urophylla & 20,5 & 27,8 & 47,0 \\
\hline $\mathrm{D}$ & E.grandis $x$ urophylla & 20,8 & 31,2 & 45,4 \\
\hline $\mathrm{E}$ & E.grandis & 21,4 & 21,2 & 33,9 \\
\hline $\mathrm{F}$ & E.grandis $x$ urophylla & 17,0 & 23,0 & 40,0 \\
\hline G & E.grandis $x$ urophylla & 17,3 & 24,8 & 43,9 \\
\hline $\mathrm{H}$ & E.grandis & 15,6 & 21,3 & 39,5 \\
\hline I & E.grandis $x$ urophylla & 18,1 & 29,0 & 46,1 \\
\hline $\mathrm{J}$ & E.grandis $x$ urophylla & 22,3 & 28,5 & 50,0 \\
\hline
\end{tabular}

\section{Dimensões das fibras}

Os clones analisados apresentaram comprimento médio de fibras de $0,99 \mathrm{~mm}$, com pequena variabilidade, de apenas 0,95 a $1,07 \mathrm{~mm}$, com coeficientes de variação mínimo e máximo de 12,7 e 18,1\%, conforme mostrado no Quadro 2. Essa pequena variabilidade é comumente observada entre clones de eucalipto e, também, pode ser atribuída às pequenas variações inerentes à técnica de medição utilizada, que consistiu no uso de microscópio óptico-digital computadorizado e na medição de apenas fibras inteiras, desconsiderando-se pedaços de fibras. As fibras apresentaram, também, pequena variabilidade na largura, com valor médio de $18,2 \mu \mathrm{m}$, para todos os clones, com coeficientes de variação mínimo e máximo de 13,3 e $18,5 \%$, respectivamente. Do mesmo modo que para comprimento e largura, as fibras apresentaram dimensões de diâmetro de lúmen e espessura de parede típicos de valores observados no Brasil em madeiras de Eucalyptus, apenas com coeficientes de variação mais altos, atribuídos possivelmente às maiores variações de diâmetro de lúmen.

O conhecimento das características anatômicas dos elementos fibrosos das polpas permite que sejam previstas indicações das propriedades de seus papéis. A qualidade do papel é influenciada pelas características morfológicas das fibras e pela quantidade destas por unidade de massa. Uma característica importante das fibras para papéis de impressão "high bulk" e "tissue" é a espessura de parede celular que, também, pode ser correlacionada com o "coarseness" da polpa. Em geral, polpas produzidas com uma mesma espécie florestal que apresentam fibras com maiores espessuras de paredes tendem a produzir polpas com maiores "coarseness" e papéis com volumes específicos aparentes mais elevados. Essas características podem contribuir favoravelmente para a maciez dos papéis "tissues" e para opacidade dos papéis de imprimir. A opacidade pode ser melhorada com a utilização de polpa com maior número de fibras por grama, em razão do maior número de superfícies ópticas para a dispersão de luz na estrutura do papel. As fibras mais curtas contribuem para uma boa formação da folha, enquanto as fibras mais longas favorecem a resistência ao rasgo. A variabilidade encontrada entre os clones indica que possivelmente os clones deverão apresentar polpas com comportamentos diferenciados, tanto no processo de formação das folhas quanto nas propriedades do papel.

R. Árvore, Viçosa-MG, v.29, n.1, p.129-137, 2005 
Quadro 2 - Características dimensionais das fibras dos clones dos Eucalyptus sp Table 2 -Dimensional characteristics of Eucalyptus clones fibers

\begin{tabular}{|c|c|c|c|c|c|c|c|c|c|c|}
\hline \multirow[t]{2}{*}{$\overline{\text { Clones }}$} & \multicolumn{2}{|c|}{$\begin{array}{c}\text { Comprimento, } \\
\mathrm{mm}\end{array}$} & \multicolumn{2}{|c|}{$\begin{array}{c}\text { Largura, } \\
\mu \mathrm{m}\end{array}$} & \multicolumn{2}{|c|}{$\begin{array}{l}\text { Diâmetro } \\
\text { Lume, } \mu \mathrm{m}\end{array}$} & \multicolumn{2}{|c|}{$\begin{array}{c}\text { Espessura } \\
\text { Parede, } \mu \mathrm{m}\end{array}$} & \multirow{2}{*}{$\begin{array}{r}\begin{array}{c}\mathrm{N}^{\circ} \text { fibras/ } \\
\text { Grama } \\
\text { (milhões) }\end{array} \\
\text { Média }\end{array}$} & \multirow{2}{*}{$\begin{array}{r}\begin{array}{r}\text { Coarsenss } \\
(\mathrm{mg} / 100 \mathrm{~m})\end{array} \\
\text { Média }\end{array}$} \\
\hline & Média & $\mathrm{CV}, \%$ & Média & $\mathrm{CV}, \%$ & Média & $\mathrm{CV}, \%$ & Média & $\mathrm{CV}, \%$ & & \\
\hline A & 0,98 & 12,7 & 17,9 & 17,2 & 8,1 & 31,2 & 4,9 & 17,1 & 19,8 & 6,9 \\
\hline B & 1,00 & 14,1 & 18,0 & 16,8 & 8,5 & 29,9 & 4,7 & 22,6 & 19,6 & 6,6 \\
\hline C & 1,05 & 16,7 & 17,6 & 13,3 & 8,4 & 29,2 & 4,6 & 26,6 & 20,5 & 6,3 \\
\hline D & 1,07 & 14,3 & 18,6 & 16,8 & 9,0 & 29,8 & 4,8 & 19,6 & 20,3 & 6,3 \\
\hline E & 0,96 & 15,6 & 18,8 & 16,2 & 8,8 & 34,3 & 5,0 & 19,3 & 20,7 & 6,6 \\
\hline $\mathrm{F}$ & 1,02 & 17,9 & 17,3 & 15,1 & 7,5 & 31,4 & 4,9 & 21,3 & 21,3 & 6,0 \\
\hline G & 0,98 & 18,1 & 18,2 & 17,2 & 8,4 & 34,0 & 4,9 & 18,9 & 25,3 & 5,8 \\
\hline $\mathrm{H}$ & 0,95 & 13,6 & 17,7 & 17,4 & 8,0 & 33,9 & 4,8 & 17,9 & 27,7 & 5,1 \\
\hline I & 0,96 & 13,8 & 19,2 & 18,5 & 8,9 & 42,5 & 5,2 & 20,5 & 16,3 & 8,3 \\
\hline $\mathrm{J}$ & 0,97 & 12,8 & 18,3 & 17,6 & 8,4 & 31,5 & 5,0 & 21,5 & 19,7 & 7,0 \\
\hline
\end{tabular}

\section{Densidade básica dos clones de Eucalyptus}

No Quadro 3 são apresentadas as densidades básicas das madeiras dos clones de Eucalyptus.

Estudos realizados com madeiras de clones de Eucalyptus (LANNA et al., 2001) têm demonstrado vantagens na utilização de madeiras com densidades básicas mais baixas. Essas vantagens corresponderiam à necessidade de utilização de menores cargas alcalinas, com reflexos favoráveis no rendimento e viscosidade da polpa celulósica e, também, na carga mais baixa de sólidos para o setor de recuperação. Considerando que na produção industrial procuram-se manter os parâmetros de tempo e temperatura com pequena variabilidade, o uso de densidades mais altas requer cargas de álcali mais elevadas para possibilitar maior eficiência de difusão dos íons e obtenção do kappa objetivo. A utilização de madeiras de baixa densidade, entretanto, irá resultar em consumo específico de madeira mais elevado, o que constitui significativa desvantagem, principalmente quando a empresa possui alguma limitação no fornecimento de matéria-prima. No entanto, estudos realizados com diferentes espécies de Eucalyptus não encontraram correlações bem definidas entre a densidade básica da madeira e a demanda de carga de álcali ou o rendimento do processo (MOKFIENSKI et al., 2003).

Quadro 3 - Densidade básica e constituição química dos clones de Eucalyptus sp

Table 3 - Basic density and chemical composition of Eucalyptus clones

\begin{tabular}{ccccccc}
\hline Clone & $\begin{array}{c}\text { Densidade } \\
\text { Básica, } \mathrm{kg} / \mathrm{m}^{3}\end{array}$ & $\begin{array}{c}\text { Solubilidade } \\
\text { Álcool/Tolueno, } \%\end{array}$ & $\begin{array}{c}\text { Solubilidade } \\
\text { Diclorometano, } \%\end{array}$ & \multicolumn{3}{c}{ Lignina Klason, \% } \\
\cline { 5 - 8 } & 510 & 4,13 & 0,18 & 27,0 & 3,5 & 30,5 \\
A & 465 & 1,76 & 0,10 & 22,4 & 5,1 & 27,5 \\
B & 482 & 2,88 & 0,14 & 27,1 & 3,5 & 30,6 \\
C & 472 & 1,99 & 0,06 & 24,9 & 3,3 & 28,2 \\
D & 486 & 3,37 & 0,20 & 26,4 & 3,7 & 30,1 \\
E & 505 & 2,12 & 0,40 & 24,2 & 3,3 & 27,5 \\
F & 503 & 3,54 & 0,50 & 24,8 & 4,4 & 29,2 \\
G & 482 & 3,30 & 0,38 & 28,6 & 3,1 & 31,7 \\
H & 490 & 3,52 & 0,40 & 24,2 & 3,6 & 27,8 \\
I & 501 & 3,45 & 0,13 & 26,0 & 3,9 & 29,9 \\
J & & & &
\end{tabular}

R. Árvore, Viçosa-MG, v.29, n.1, p.129-137, 2005 
A densidade da madeira representa o somatório de diversas características da madeira, e nem sempre é possível estabelecer correlações perfeitas entre os resultados da produção de celulose e essa característica da madeira. Modernamente, os novos projetos de ampliação de capacidade de produção das fábricas e de implantação de novas fábricas têm priorizado a utilização de madeira com densidade próxima a $500 \mathrm{~kg} / \mathrm{m}^{3}$.

Neste estudo, apenas $40 \%$ das madeiras apresentaram densidade básica acima de $500 \mathrm{~kg} / \mathrm{m}^{3}$, e as densidades dos demais clones variaram de 465 a $490 \mathrm{~kg} / \mathrm{m}^{3}$. Esses resultados indicam que as empresas nacionais de celulose têm priorizado, na seleção de clones, densidades básicas próximas a $500 \mathrm{~kg} / \mathrm{m}^{3}$, com tendência para densidades ligeiramente inferiores.

\section{Teores de extrativos e de lignina das madeiras dos clones de Eucalyptus}

As madeiras analisadas neste estudo apresentaram considerável variabilidade nos teores de extrativos e de lignina, conforme demonstrado no Quadro 3. Os extrativos solúveis em álcool/tolueno variaram desde 1,76 até $4,13 \%$. Os clones com maiores teores de extrativos deverão apresentar menor rendimento da polpação, com perdas de até $4 \%$ no rendimento, devido exclusivamente à remoção dos extrativos. Os extrativos hidrofóbicos, solúveis em DCM e fonte potencial de formação de "pitch", também apresentaram considerável variação, desde 0,06 até $0,50 \%$. Apesar de as empresas nacionais estarem investindo fortemente em estudos de caracterização destes extrativos hidrofóbicos, as medidas práticas para minimizar a ação dos depósitos de "pitch" têm sido a adoção de medidas paliativas que consistem na utilização de aditivos, como talco, para combater seus efeitos maléficos. A seleção de clones com baixos teores de extrativos potencialmente formadores de "pitch" deverá ser priorizada pelas empresas brasileiras de celulose branqueada de eucalipto.

Os clones de Eucalyptus utilizados neste estudo apresentaram teores de lignina que variaram de 27,5 até $31,7 \%$. Esses valores indicaram que, mesmo sendo madeira de folhosa, alguns clones de eucalipto plantados no Brasil atingem teores de lignina acima de $30 \%$, teores mais característicos de madeiras de coníferas. $\mathrm{O}$ teor de lignina com estruturas químicas menos resistentes à degradação e solubilização, determinadas como lignina
Klason solúvel, como é característico das madeiras de folhosas, variou de 3,1 a 5,1\%. Apesar de ser uma generalização não confirmada, este tipo de lignina talvez seja, também, mais facilmente removido durante o cozimento alcalino kraft. A lignina das madeiras de eucalipto apresentou, caracteristicamente, maiores teores de estruturas tipo siringil que as do tipo guaiacil, como mostrado no Quadro 4.

As estruturas de lignina siringil, por não possuírem o carbono reativo C5 disponível para reação na etapa de polimerização da biossíntese da lignina, apresentam estrutura química menos condensada e, conseqüentemente, são mais favoráveis à deslignificação pelo licor de cozimento kraft. A relação entre as estruturas siringil e guaiacil (S/G) demonstrou que nas madeiras de eucalipto analisadas a freqüência das estruturas siringil é de duas a três vezes maior que a das estruturas guaiacil. Outras espécies de Eucalyptus, como o $E$. globulus, apresentam teores mais elevados de grupos siringil, com relação S/G de 4,7 (MOKFIENSKI et al., 2003), o que seria uma característica desejável para os clones de eucaliptos nacionais.

\section{Constituição de carboidratos dos clones de Eucalyptus}

A constituição da fração de carboidratos das madeiras dos clones de Eucalyptus está apresentada no Quadro 5.

As glucanas exibiram pouco menos da metade da constituição química da madeira, em média $46,6 \%$ do peso das madeiras, enquanto as xilanas foram a fração dominante das hemiceluloses, representando de 10,8 a $13,2 \%$.

Quadro 4-Teores de siringil e guaiacil dos clones de Eucalyptus $\mathrm{sp}$

Table 4 - Siringil and guaiacil content of Eucalyptus clones

\begin{tabular}{cccc}
\hline Clones & $\begin{array}{c}\text { Siringil } \\
(\mathrm{mmol})\end{array}$ & $\begin{array}{c}\text { Guaiacil } \\
(\mathrm{mmol})\end{array}$ & $\begin{array}{c}\text { Relação Siringil/ } \\
\text { Guaiacil }\end{array}$ \\
\hline A & 1,82 & 0,83 & 2,2 \\
B & 2,04 & 0,81 & 2,5 \\
C & 1,70 & 0,74 & 2,3 \\
D & 1,88 & 0,88 & 2,1 \\
E & 1,91 & 0,77 & 2,5 \\
F & 1,88 & 0,85 & 2,2 \\
G & 2,19 & 1,01 & 2,2 \\
H & 1,98 & 1,00 & 2,0 \\
I & 1,83 & 0,66 & 2,8 \\
J & 2,26 & 0,97 & 2,4 \\
\hline
\end{tabular}

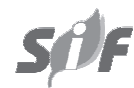

R. Árvore, Viçosa-MG, v.29, n.1, p.129-137, 2005 
Quadro 5 - Análise de carboidratos dos clones de Eucalyptus sp Table 5 - Carbohydrate analysis of Eucalyptus clones

\begin{tabular}{|c|c|c|c|c|c|c|c|c|}
\hline Clones & $\begin{array}{c}\text { Glucanas } \\
\%\end{array}$ & $\begin{array}{c}\text { Xilanas } \\
\%\end{array}$ & $\begin{array}{c}\text { Galactanas } \\
\%\end{array}$ & $\begin{array}{c}\text { Mananas } \\
\%\end{array}$ & $\begin{array}{c}\text { Arabinanas } \\
\%\end{array}$ & $\begin{array}{c}\text { Ácidos } \\
\text { Urônicos,\% }\end{array}$ & $\begin{array}{c}\text { Grupos } \\
\text { Acetila, \% }\end{array}$ & $\begin{array}{c}\text { Acetila/ } \\
10 \mathrm{Xiloses}\end{array}$ \\
\hline $\mathrm{A}$ & 45,0 & 11,5 & 0,9 & 0,6 & 0,3 & 3,8 & 2,9 & 6,8 \\
\hline B & 49,2 & 13,2 & 0,8 & 0,6 & 0,3 & 3,2 & 3,0 & 6,1 \\
\hline $\mathrm{C}$ & 47,8 & 10,8 & 0,7 & 0,4 & 0,1 & 3,7 & 2,6 & 6,5 \\
\hline D & 50,0 & 11,1 & 0,8 & 0,3 & 0,2 & 4,3 & 2,6 & 6,3 \\
\hline $\mathrm{E}$ & 44,6 & 12,8 & 0,5 & 0,5 & 0,3 & 4,4 & 2,9 & 6,1 \\
\hline $\mathrm{F}$ & 47,6 & 13,1 & 0,6 & 0,9 & 0,2 & 4,6 & 3,0 & 6,2 \\
\hline G & 45,7 & 11,6 & 0,8 & 0,6 & 0,3 & 4,7 & 3,1 & 7,2 \\
\hline $\mathrm{H}$ & 44,5 & 11,8 & 0,7 & 0,6 & 0,1 & 3,9 & 2,8 & 6,4 \\
\hline I & 46,5 & 13,2 & 0,6 & 0,7 & 0,3 & 3,9 & 2,9 & 5,9 \\
\hline $\mathbf{J}$ & 44,8 & 12,7 & 0,6 & 0,7 & 0,3 & 4,3 & 2,7 & 5,7 \\
\hline
\end{tabular}

Os outros carboidratos, incluindo as galactanas, as mananas e as arabinanas constituíram, cada uma delas, menos de $1 \%$ do peso da madeira. As arabinanas foram a menor fração de carboidratos da madeira, constituindo, em média, apenas $0,2 \%$ da madeira. Na constituição química das xilanas foram determinados, além da unidade monomérica básica de xilose, os teores dos grupos laterais conectados à cadeia básica, abrangendo os ácidos urônicos e os grupos acetila. Os ácidos urônicos, incluindo os glucurônicos e os galacturônicos, representaram uma fração significativa da madeira, em média cerca de $4 \%$ do seu peso. A importância desses grupos das xilanas está relacionada com o consumo de álcali durante a polpação, com conseqüente hidrólise e dissolução, e com a transformação em ácidos hexenurônicos, indesejáveis nas operações de branqueamento. $\mathrm{O}$ teor dos grupos laterais de acetila das cadeias de xilanas foi bastante constante, tendo variado apenas de 2,6 a 3,1\%. A presença de grupos acetila nas xilanas constitui uma desvantagem tecnológica, pois, além de consumir álcali durante o cozimento kraft, representa perda de rendimento, uma vez que são totalmente hidrolisados e solubilizados durante o cozimento (GOMIDE, 2000). Os clones de Eucalyptus analisados apresentaram alta freqüência de grupos laterais de acetila nas cadeias de xilanas, em média mais de seis grupos acetila para 10 unidades de xilose. Uma análise mais global das madeiras de Eucalyptus demonstrou (Quadro 6) que o teor de hemiceluloses, incluindo seus grupos laterais, constituiu, em média, mais de $21 \%$ do peso da madeira, tendo apresentado bastante variabilidade, desde 18,6 até $23,2 \%$.
Do mesmo modo, o teor de celulose nas madeiras apresentou significativa variação, desde 43,9 até 49,7\%.

\section{Características de polpação dos clones de Eucalyptus}

As características tecnológicas dos clones de Eucalyptus foram determinadas simulando-se em laboratório uma das modernas tecnologias para produção de celulose kraft. A tecnologia selecionada consistiu na utilização de vaso de impregnação, de temperatura máxima de cozimento significativamente inferior às técnicas convencionais e de injeções parceladas da carga de álcali. Essas condições proporcionaram deslignificação mais seletiva, possibilitando maximização de qualidade da polpa celulósica. Os resultados da produção de polpa celulósica com as madeiras dos 10 clones utilizados estão apresentados no Quadro 7.

Quadro 6 - Teores de celulose e hemiceluloses dos clones de Eucalyptus sp

Table 6-Cellulose and hemicelluloses content of Eucalyptus clones

\begin{tabular}{cccc}
\hline Clones & $\begin{array}{c}\text { Celulose, } \\
\%\end{array}$ & $\begin{array}{c}\text { Hemiceluloses, } \\
\%\end{array}$ & $\begin{array}{c}\text { Holocelulose, } \\
\%\end{array}$ \\
\hline A & 44,4 & 20,5 & 64,9 \\
B & 48,6 & 21,6 & 70,2 \\
C & 47,4 & 18,6 & 66,0 \\
D & 49,7 & 19,6 & 69,3 \\
E & 44,1 & 21,9 & 66,0 \\
F & 46,7 & 23,2 & 69,9 \\
G & 45,0 & 21,8 & 66,8 \\
H & 43,9 & 20,6 & 64,5 \\
I & 45,8 & 22,4 & 68,2 \\
J & 44,1 & 22,0 & 66,1 \\
\hline
\end{tabular}


Quadro 7 - Polpação kraft dos clones de Eucalyptus sp Table 7 - Kraft pulping of Eucalyptus clones

\begin{tabular}{|c|c|c|c|c|c|c|c|}
\hline \multirow[t]{2}{*}{ Clone } & \multirow{2}{*}{$\begin{array}{c}\mathrm{AE} \\
\%\end{array}$} & \multirow{2}{*}{$\begin{array}{l}\text { Número } \\
\text { Kappa }\end{array}$} & \multicolumn{3}{|c|}{ Rendimentos, $\%$} & \multirow{2}{*}{$\begin{array}{c}\text { Viscosidade, } \\
\text { cP }\end{array}$} & \multirow{2}{*}{$\begin{array}{l}\text { Ac. Hex. } \\
\mathrm{mmol} / \mathrm{kg}\end{array}$} \\
\hline & & & Depurado & Rejeitos & Total & & \\
\hline $\mathrm{A}$ & 18,5 & 17,8 & 50,2 & 0,0 & 50,2 & 59,1 & 54,0 \\
\hline B & 13,7 & 17,7 & 57,6 & 0,0 & 57,6 & 129,6 & 34,7 \\
\hline $\mathrm{C}$ & 16,0 & 18,0 & 53,4 & 0,0 & 53,4 & 76,1 & 44,9 \\
\hline $\mathrm{D}$ & 15,5 & 18,0 & 55,4 & 0,0 & 55,4 & 80,8 & 50,7 \\
\hline $\mathrm{E}$ & 17,5 & 18,5 & 50,8 & 0,0 & 50,8 & 71,7 & 57,9 \\
\hline $\mathrm{F}$ & 15,0 & 17,8 & 54,5 & 0,0 & 54,5 & 99,9 & 51,7 \\
\hline $\mathrm{G}$ & 15,5 & 18,3 & 52,3 & 0,0 & 52,3 & 108,0 & 43,1 \\
\hline $\mathrm{H}$ & 19,0 & 18,0 & 49,3 & 0,0 & 49,3 & 60,4 & 54,5 \\
\hline I & 15,8 & 17,8 & 54,3 & 0,0 & 54,3 & 98,7 & 46,6 \\
\hline $\mathbf{J}$ & 17,0 & 18,2 & 51,1 & 0,0 & 51,1 & 71,8 & 48,5 \\
\hline
\end{tabular}

Considerando que os clones analisados constituem uma amostragem representativa dos melhores clones de Eucalyptus atualmente utilizados no Brasil para produção de celulose, os resultados indicaram que existe uma variação significativa de qualidade da madeira utilizada no país para a produção de celulose. As polpas de todos os clones apresentaram similaridade de número kappa, dentro dos limites preestabelecidos de $18 \pm$ 0,5 , o que possibilita análises comparativas das suas características de polpação.

A demanda de carga de álcali para produção de celulose com kappa 18 apresentou extensa variação, desde 13,7 até 19,0\%. Demanda de altas cargas de álcali constitui uma característica altamente desfavorável, uma vez que provoca perda de rendimento, degradação mais intensa das cadeias dos carboidratos, sobrecarga da caldeira de recuperação e aumento do custo de produção.

A utilização de diferentes cargas de álcali resultou em polpas com propriedades e características significativamente distintas. Um dos clones (clone B) apresentou rendimento depurado excepcionalmente alto para espécies de Eucalyptus industrialmente utilizadas no Brasil, atingindo 57,6\%. Esse elevado rendimento poderia ser explicado pelas características favoráveis da madeira, que apresentava baixos valores de densidade básica, de extrativos, de lignina, de ácidos urônicos, de grupos acetila e altos teores de celulose e de relação siringil/guaiacil. Deve ser considerado que a densidade básica do clone $\mathrm{B}$ foi relativamente baixa, de $465 \mathrm{~kg} / \mathrm{m}^{3}$, o que irá resultar em consumo específico de madeira mais elevado, mesmo com o elevado rendimento da polpação. No entanto, um dos clones, o clone $\mathrm{H}$, apresentou rendimento de $49,3 \%$, o que pode ser considerado baixo para programas de melhoramento florestal no Brasil. Do mesmo modo, o rendimento inferior do clone $\mathrm{H}$ pode ser explicado pelas características desfavoráveis da madeira, à exceção da densidade básica, que foi de $482 \mathrm{~kg} / \mathrm{m}^{3}$. De modo geral, no Brasil estabelece-se um rendimento de $50 \%$ como limite inferior para seleção de clones, e, dos 10 clones analisados, apenas um proporcionou rendimento inferior a esse limite. Numa análise global, a média dos rendimentos foi próxima de $53 \%$, e cerca de $60 \%$ dos clones apresentaram rendimentos superiores a 52\%, demonstrando a alta qualidade dos clones de Eucalyptus no Brasil.

Além do rendimento, as polpas celulósicas apresentaram ampla variação da viscosidade, atingindo quase $220 \%$; novamente, o clone B se destacou com viscosidade excepcionalmente alta de 129,6 cP. Elevadas viscosidades podem ser indicadoras de boa qualidade da polpa, mas não necessariamente determinam alta resistência mecânica das fibras e, consequientemente, da polpa. O valor mais baixo de viscosidade, correspondente a 59,1 cP, foi ainda suficientemente alto como critério de qualidade da polpa não branqueada kraft de Eucalyptus. A elevada viscosidade média das polpas, 85,6 cP, evidencia a alta qualidade da madeira dos clones nacionais de Eucalyptus para produção de celulose.

A utilização de recentes técnicas de branqueamento sem o estágio inicial de cloração, os denominados branqueamentos ECF, tornou importante o teor de ácidos hexenurônicos na polpa kraft não branqueada de folhosas. A importância dos ácidos hexenurônicos é conseqüência

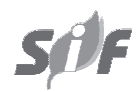

R. Árvore, Viçosa-MG, v.29, n.1, p.129-137, 2005 
do consumo de reagentes do branqueamento, o dióxido de cloro e o ozônio, causado por essas estruturas químicas na cadeia lateral das xilanas. Durante o cozimento kraft, parte dos ácidos urônicos é transformada em ácidos hexenurônicos. A formação dos ácidos hexenurônicos é influenciada pelas características de constituição química da madeira e, entre outros fatores, pela carga alcalina utilizada na polpação. Neste estudo, foram determinados os teores de ácidos hexenurônicos nas polpas celulósicas, e os resultados estão apresentados no Quadro 7. As diferentes cargas de álcali utilizadas, associadas aos diferentes teores de ácidos urônicos originalmente presentes nas madeiras, resultaram em teores de ácidos hexenurônicos significativamente diferentes. O teor de ácidos hexenurônicos nas polpas apresentou variação de mais de $65 \%$, com valores variando desde 34,7 até $57,9 \mathrm{mmol} /$ $\mathrm{kg}$. Para verificar o efeito da carga alcalina e do teor de grupos urônicos originalmente presente na madeira na formação de ácidos hexenurônicos, foram realizadas análises estatísticas de correlação, estando os resultados apresentados nas Figuras 2 e 3. Como demonstrado na Figura 2, a carga alcalina utilizada na polpação apresentou efeito significativo na formação dos ácidos hexenurônicos, com coeficiente de correlação de quase $77 \%$. Apesar de não ser uma correlação muito elevada, observou-se claramente que o aumento da carga de

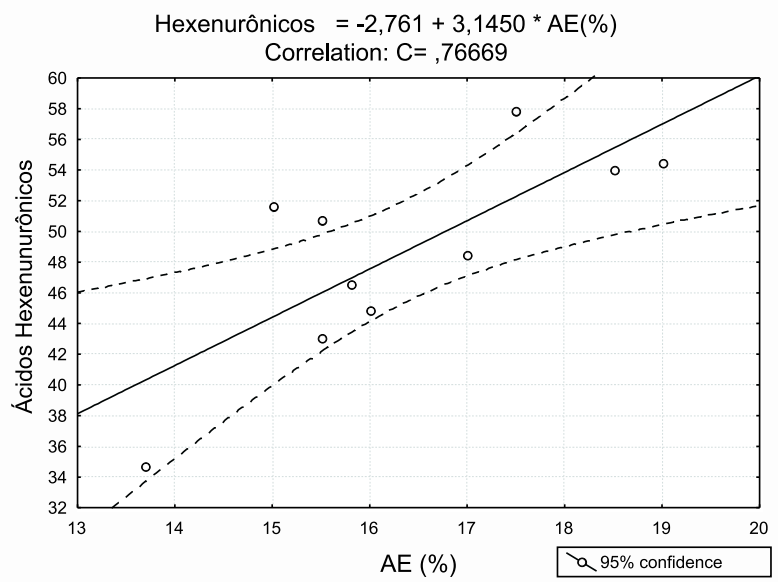

Figura 2 - Correlação de ácidos hexenurônicos e álcali efetivo do cozimento.

Figure 2 - Correlation of hexenuronic acids and effective alkali.

R. Árvore, Viçosa-MG, v.29, n.1, p.129-137, 2005 álcali proporcionou, como tendência geral, maior formação de ácidos hexenurônicos na polpa celulósica. No entanto, o teor de grupos urônicos na madeira não apresentou correlação com a formação de estruturas de ácidos hexenurônicos. Como os ácidos hexenurônicos são formados a partir dos ácidos urônicos, poder-se-ia esperar alguma correlação entre eles, o que não ocorreu, talvez pela grande variabilidade da carga de álcali utilizada.

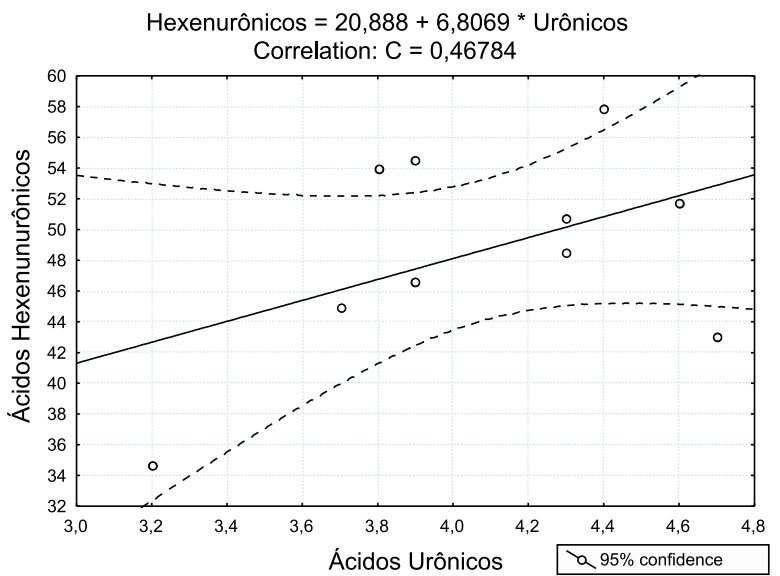

Figura 3 - Correlação dos ácidos hexenurônicos e urônicos na madeira.

Figure 3 -Correlation of hexenuronic and uronic acids.

\section{CONCLUSÕES}

Os resultados deste estudo indicam a alta qualidade tecnológica dos clones de Eucalyptus atualmente utilizados no Brasil pelas principais empresas produtores de celulose kraft branqueada. Essa qualidade é comprovada pelo alto rendimento de polpação dos clones, que apresentaram um rendimento médio de 52,9\%; um clone proporcionou rendimento inferior a $50 \%$; e um dos clones teve rendimento excepcionalmente elevado de 57,6\%. Nas décadas de 1980 e 1990, nos programas nacionais de melhoramento genético objetivava-se, em geral, selecionar clones que proporcionassem rendimentos superiores a $50 \%$, o que foi plenamente alcançado, conforme demonstrado neste estudo. A utilização do rendimento de polpação como parâmetro global de qualidade é perfeitamente válido, uma vez que essa característica tecnológica é consequiência de vários fatores, englobando as características anatômicas e químicas da madeira e a demanda de álcali para a produção de polpa celulósica. 


\section{REFERÊNCIAS BIBLIOGRÁFICAS}

\author{
ASSOCIAÇÃO BRASILEIRA TÉCNICA DE \\ CELULOSE E PAPEL-ABTCP. Normas. São \\ Paulo, ABTCP, s/d.
}

ENGLYST, H.N.; CUMMINGS, J.H. Simplified method for the measurement of total non-starch polysaccharide by gas-liquid chromatography of constituent sugara as alditol-acetates. Analyst, v.109, n.7, p.937-942. 1984.

GOLDSCHMID, O. Ultraviolet spectra. In: SARKANEN, K.V.; LUDWIG, C.H. (Eds). Lignins. New York: Wiley-Interscience, 1971. p.241-266.

GOMIDE, J.L.; FANTUZZI NETO, H. Aspectos fundamentais da polpação kraft de madeira de Eucalyptus. O Papel, v.3 n. 61, p. 62-68, 2000.

GOMIDE, J.L.; DEMUNER, B.J. Determinação do teor de lignina em material lenhoso: Método Klason modificado. O Papel, v.47, n.8 p.36-38, 1986.

GRACE, T.M. et al., (Ed.) Kraft liquors. In: GRACE, T.M.; LEOPOLD, B.; MALCON, E.W. Pulp and paper manufacture - Alkaline pulping. Atlanta: Tappi, 1989. v.5, p.15-22.
LANNA, A.E. et al. Maximizing pulp yield potential of Cenibra's wood supply. In: BRAZILIAN SYMPOSIUM ON THE CHEMISTRY OF LIGNINS AND OTHER WOOD COMPONENTS. 7., 2001, Belo Horizonte. Proceedings... Belo Horizonte: 2001. p159-167.

LIM, S.Y.; DENCE, C.W. Methods in lignin chemistry. Berlin: Springer-Verlag, 1992. 578p.

MOKFIENSKI, A. et al. Importância da densidade e do teor de carboidratos totais da madeira de eucalipto no desempenho da linha de fibras. In: COLÓQUIO INTERNACIONAL SOBRE CELULOSE KRAFT DE EUCALIPTO. 2003, Viçosa. Colóquio... Viçosa: 2003. p15-38.

SOLAR, R.; KACIK, F.; MELCER, I. Simple semimicro method for the determination of oacetyl group in wood and related materials. Nordic Pulp \& Paper Research Journal. v.4, p.139-141, 1987.

TECHNICALASSOCIATION OF THE PULP AND PAPER INDUSTRY-TAPPI. Tappi test methods: 1992-1993. Atlanta: 1992.

VOURINEN, T. et al. Selective hydrolysis of hexenuronic acid and its application in ECF and TCF bleaching kraft pulps. In: INTERNATIONAL PULP BLEACHING CONFERENCE, 1996, Washington, Proceedings... Washington: 1996, p.43-51. 
